Original Article

\title{
Undernutrition and associated factors among hospitalized patients
}

\author{
Teresa F. Amaral ${ }^{\mathrm{a}, *}$, Luís C. Matos ${ }^{\mathrm{b}, 1}$, Maria A. Teixeira ${ }^{\mathrm{c}, 1}$, Maria M. Tavares ${ }^{\mathrm{d}, 1}$, Luísa Álvares ${ }^{\mathrm{e}, 1}$, \\ Ana Antunes $\mathrm{f}, 1$
}

${ }^{a}$ Faculdade de Ciências da Nutrição e Alimentação da Universidade do Porto, Rua Dr. Roberto Frias, 4200-465 Porto, Portugal

${ }^{\mathrm{b}}$ Hospital Geral Santo António E.P.E., Porto, Portugal

${ }^{\mathrm{c}}$ Hospital Central do Funchal, Funchal, Portugal

${ }^{\mathrm{d}}$ Hospital Pedro Hispano, ULS Matosinhos E.P.E., Serviço Regional de Saúde E.P.E., Portugal

${ }^{\text {e } C e n t r o ~ H o s p i t a l a r ~ d e ~ V i l a ~ R e a l / P e s o ~ d a ~ R e ́ g u a ~ E . P . E ., ~ V i l a ~ R e a l, ~ P o r t u g a l ~}$

${ }^{\mathrm{f}}$ Instituto Português de Oncologia Francisco Gentil E.P.E., Porto, Portugal

\section{A R T I C L E I N F O}

\section{Article history:}

Received 17 July 2009

Accepted 4 February 2010

\section{Keywords:}

Disease-related malnutrition in hospital

Undernutrition

Multicentre

NRS 2002

Education

Functional autonomy

\begin{abstract}
S U M M A R Y
Background \& aims: The identification of modifiable risk factors associated with disease-related undernutrition at hospital admission will contribute to the development of integrated intervention and control strategies for a timely primary prevention. This study aim was to quantify the association between functional autonomy and undernutrition.

Methods: A multicentric cross-sectional study was developed in six public hospitals in Portugal. Undernutrition risk was assessed using Nutritional Risk Screening 2002, undernutrition status was classified from anthropometry and functional autonomy was evaluated using the Katz Index.

Results: In this sample of 1144 patients, 36\% were at undernutrition risk and 9.7\% undernourished. In logistic regression analysis, dependent patients were at an increased risk of undernutrition $(\mathrm{OR}=1.69$, 95\% confidence interval $(\mathrm{CI})=1.20-2.39)$. The following parameters: illiteracy $(\mathrm{OR}=2.45$, $\mathrm{CI}=1.52-3.96)$, age (one year increment $)(\mathrm{OR}=1.03, \mathrm{CI}=1.02-1.04)$, male $(\mathrm{OR}=1.61, \mathrm{CI}=1.19-2.16)$, single/divorced/widowed $(\mathrm{OR}=1.83, \mathrm{CI}=1.34-2.51)$ and smoker $(\mathrm{OR}=1.55, \mathrm{CI}=1.02-2.35)$ also increased the undernutrition risk. The impaired functional status, being single, divorced or widowed and be a smoker were also associated with anthropometric undernutrition.

Conclusions: Functional impairment is related with undernutrition risk and with anthropometrical undernutrition at hospital admission. We also conclude that little extra information is gained by using anthropometrical indices compared to NRS 2002 when assessing the factors associated with undernutrition.
\end{abstract}

(c) 2010 Elsevier Ltd and European Society for Clinical Nutrition and Metabolism. All rights reserved.

\section{Introduction}

Disease-related undernutrition remains a highly prevalent condition in health care settings, affecting $15-60 \%$ of the patients at hospital admission, ${ }^{1,2}$ despite increasing awareness of its burden. Although these estimates have large variations and are dependent

Non-standard abbreviations: MMC, Mid-arm Muscle Circumference; TSF, Triceps Skinfold Thickness; BMI, Body Mass Index; NRS 2002, Nutritional Risk Screening 2002.

* Corresponding author. Faculty of Nutrition and Food Sciences, Porto University, Rua Dr. Roberto Frias, 4200465 Porto, Portugal. Tel.: +351 22507 4327; fax: +351 225074329.

E-mail addresses: amaral.tf@gmail.com (T.F. Amaral), luisrcmatos@gmail.com (L.C. Matos), afteixeira@srs.pt (M.A. Teixeira), mariamtavares@gmail.com (M.M. Tavares), luisaalvares@vodafone.pt (L. Álvares), anacerqantunes@gmail.com (A. Antunes).

1 Affiliation at the moment of data collection. on the definitions used to categorize nutritional status, as well as case mix of patients evaluated and the sampling procedures, ${ }^{1}$ recent data shows that they remain consistently high. ${ }^{2-4}$ Furthermore, there is recent evidence that strategies as regular audits and the resulting feedback leads to a decrease in undernutrition prevalence. $^{5}$

The identification of modifiable risk factors associated to disease-related undernutrition at hospital admission will contribute to the development of integrated intervention and control strategies for a timely primary prevention. The metabolic effects of underlying disease and nutritional intake deficiencies are described as major causes for disease-related undernutrition ${ }^{1}$ diagnosed at hospital admission, but there is evidence that other underlying risk factors such as advanced age, ${ }^{6,7}$ low educational status, ${ }^{6,8}$ deprivation ${ }^{9}$ and living alone, ${ }^{7}$ are also related.

The association between loss of functional autonomy and undernutrition using the Katz Index ${ }^{10}$ was described in older 
patients during hospitalization. ${ }^{11}$ The Katz Index is based on an evaluation of the functional independence or dependence in six activities of daily living. ${ }^{10}$ Undernutrition was also associated with delayed functional recovery. ${ }^{12}$ However, the association between undernutrition and the loss of functional autonomy, accounting for the identified risk factors, has not been properly quantified.

This study aim was to quantify the association between functional autonomy and undernutrition at the moment of hospital admission, independently of characteristics usually recognized as determinants of undernutrition.

\section{Subjects and methods}

\subsection{Participants}

A multicentric cross-sectional study was developed in six public hospitals in Portugal between 2004 and 2008. Results regarding nutritional status recorded in patient notes, ${ }^{13}$ screening tools evaluation, ${ }^{14,15}$ and the economic impact of undernutrition ${ }^{16}$ were previously described.

Two central university teaching hospitals, three district general hospitals and an oncology hospital were selected based on reasons of convenience. To obtain a probabilistic sample of $50 \%$ in-patients, a systematic sampling method was used. The first of every two admitted patients in weekdays who met the inclusion criteria was consecutively admitted to the study, until completing half of the number of department's beds. Patients were considered eligible if they were at least 18 years old and had a planned length of hospital stay longer than $24 \mathrm{~h}$. Exclusion criteria were pregnancy and critical illness, defined as the failure of one vital organ needing intensive care. ${ }^{17}$ All patients considered as critical, terminal or non-terminal, whether or not in an ICU unit were not included.

A total of 1173 patients were enrolled but as 29 patients had missing data, our final sample consisted of 1144 patients, 238 from Hospital Geral de Santo António SA (Hospital 1), 231 from Hospital Pedro Hispano (ULS Matosinhos, SA) (Hospital 2), 129 from Hospital de Vila Real/Peso da Régua (Hospital 3), 257 from Centro Hospitalar do Funchal (Hospital 4) 159 from Hospital Senhora da Oliveira, Guimarães (Hospital 5) and 130 from Instituto Português de Oncologia do Porto Francisco Gentil (Hospital 6).

The study protocol was approved by the institutional board and ethics committee of each hospital and was conducted according to the Declaration of Helsinki. ${ }^{18}$ As part of ethical screening practice, participants identified as being at undernutrition risk or undernourished were referred to their doctors and clinical nutritionists.

\subsection{Nutritional status variables}

Undernutrition risk was assessed using Nutritional Risk Screening 2002 (NRS 2002). ${ }^{19}$ NRS 2002 classifies the patient nutritional risk status in four categories based on Body Mass Index (BMI), percentage of recent weight loss, recent change in food intake and disease severity. ${ }^{19}$

Each patient undernutrition status was classified from anthropometric data, with an association of Mid-arm Muscle Circumference (MMC) or Triceps Skinfold Thickness (TSF) with Body Mass Index (BMI). ${ }^{20}$ Anthropometric data were collected applying standard procedures. ${ }^{21}$ Patients were weighed wearing light clothes using a mechanical scale to the nearest $0.1 \mathrm{~kg}$. In immobilized patients, we used the patients' weight as reported in the clinical file or if weight was unavailable, this was obtained from the patient or relatives or estimated by the interviewers. Height was measured with a fixed tape to the nearest $0.1 \mathrm{~cm}$, and recumbent height was obtained in patients who were unable to stand up. Weight and height were used to calculate BMI (weight $[\mathrm{kg}] /(\text { height }[\mathrm{m}])^{2}$ ).
Mid-arm circumference was measured with a tape and TSF was measured three times with a Harpenden skinfold calliper, to the nearest $0.2 \mathrm{~mm}$, and the mean was calculated. The measurements were made in the non-dominant arm. When the non-dominant arm was injured, paralysed or with peripheral vascular access, the dominant arm was used. MMC was calculated from TSF and midarm circumference using the formula devised by Jelliffe (1966). ${ }^{22}$ For patients aged $<65$ years, values from TSF measurements were compared with Frisancho (1981) reference data ${ }^{23}$ and MMC with Bishop et al. (1981). ${ }^{24}$ For patients aged $\geq 65$ years, the Corish et al. $(2003)^{25}$ reference values were used. Patients were classified with anthropometrical undernutrition if BMI $<18.5 \mathrm{~kg} / \mathrm{m}^{2}$ or if BMI $<20.0 \mathrm{~kg} / \mathrm{m}^{2}$ and TSF or MMC values were under the 15 th centile. ${ }^{20}$ Patients with ascites and/or oedema $(n=100)$ were excluded from this analysis.

\subsection{Other variables}

The functional autonomy was evaluated using the Katz Index for independence in daily living activities. ${ }^{10}$ Independence was defined as being able to perform the activities such as moving/walking, dressing, eating, bathing, personal hygiene without the assistance of another person and not presenting urinary/faecal incontinence. Patients were scored according to their performance in each of these six categories of activities, 0 if dependent and 1 if independent. The patient was considered totally dependent if unable to perform more than two of these activities; partially dependent if able to perform three to five activities; and totally independent if able to perform six activities. This is a reliable, valid and widely used index. ${ }^{10}$

Social and demographical information which include age, sex, marital status, education level (number of completed years of schooling) and tobacco use was collected. Patients were classified as smokers if they smoke one or more cigarettes or cigars per day. Clinical information concerning primary diagnosis, the presence of oedema and ascites was collected from clinical file.

All the data was collected by the same interviewer in each hospital. In order to improve intra and inter interviewer agreement, all the procedures were previously trained.

\subsection{Statistical analysis}

Frequencies were compared using Chi-square test. The association between the explored factors and undernutrition was calculated by means of odds ratios (OR) and 95\% confidence intervals (CI), comparing the highest versus the lowest category. Using nonconditional logistic regression models, the underlying disease, biological characteristics (sex, age), social parameters (education, married/marriage like), functional autonomy and smoking habits were investigated factors associated with both the risk of undernutrition and anthropometrical undernutrition. A logistic regression model, using our sample of patients aged $\geq 65$ years, was conducted to study whether the association between the evaluated factors and undernutrition or undernutrition risk was similar to those identified when the entire sample was analyzed. For these analyses, the crude and the adjusted OR of each variable were determined. All the statistical analysis was performed with SPSS statistical software (V14.0). Results were considered significant when $p<0.05$.

\section{Results}

Undernutrition risk evaluation by NRS 2002 at admission in this multicentric study carried out in six Portuguese hospitals revealed that $36 \%$ of patients were at risk. This proportion 
Table 1

Sample characterization by hospital.

\begin{tabular}{|c|c|c|c|c|c|c|}
\hline Hospitals & 1 & 2 & 3 & 4 & 5 & 6 \\
\hline$N$ & 238 & 231 & 129 & 257 & 159 & 130 \\
\hline Type of patients & Medical Surgical & Medical Surgical & Medical Surgical & Medical Surgical & Medical Surgical & Oncological \\
\hline Hospital type & University Central & University Central & District & Central & District & Central \\
\hline Undernutrition risk ${ }^{\mathrm{a}}$ & $111(46.6)$ & $87(37.7)$ & $43(33.3)$ & $88(34.2)$ & $46(28.9)$ & $37(28.5)$ \\
\hline Undernourished $^{\mathrm{b}}$ & $31(14.9)$ & $18(8.3)$ & $14(12.2)$ & $17(7.3)$ & $9(6.3)$ & $12(9.5)$ \\
\hline
\end{tabular}

a Results are expressed as number and (\%) in each hospital, total sample of $n=1144$

b Results are expressed as number and (\%) in each hospital, total sample of $n=1044$.

ranged between $46.6 \%$ in a central university teaching hospital and $28.5 \%$ in a central oncologic hospital. The anthropometrical criteria evaluation allowed the identification of $9.7 \%$ undernourished individuals with the highest frequency (14.9\%) and the lowest $(6.3 \%)$ found in patients from district hospitals (Table 1).

The sample characteristics are described according to undernutrition risk (NRS 2002) and anthropometrical undernutrition status in Table 2. The patients involved in this study presented a mean age of 57.5 years (SD: 17.9 years). The group of at undernutrition risk patients had a higher proportion of elderly $(\geq 65$ years) than those who were not at risk. Patients at undernutrition risk and with anthropometrical undernutrition had a lower education status, were more likely to be single, divorced or widowed and to have an impaired functional status, compared to those without those nutritional conditions. Smokers were more frequent in the group of patients with anthropometrical undernutrition.

The crude and multivariate adjusted odds ratios for the association of the studied parameters with undernutrition risk are presented in Table 3. In a multivariate logistic regression model, the loss of functional autonomy was significantly associated with undernutrition risk. Dependent patients were at an increased risk of undernutrition $\mathrm{OR}=1.69(\mathrm{CI}=1.20-2.39)$ compared to patients able to perform all the evaluated daily living activities. Illiteracy was the strongest risk factor associated with undernutrition risk, with an adjusted $\mathrm{OR}=2.45(\mathrm{CI}=1.52-3.96)$. Age was also strongly associated with an increased undernutrition risk, one year increment increased $3 \%$ the undernutrition risk $(\mathrm{OR}=1.03$, $\mathrm{CI}=1.02-1.04)$. Furthermore, being male $(\mathrm{OR}=1.61$, $\mathrm{CI}=1.19-2.16), \quad$ single/divorced/widowed $(\mathrm{OR}=1.83$, $\mathrm{CI}=1.34-2.51)$ or a smoker $(\mathrm{OR}=1.55, \mathrm{CI}=1.02-2.35)$ also increased the undernutrition risk. Compared to patients submitted to non-surgical treatment, patients submitted to surgical treatment showed a decreased undernutrition risk (OR $=0.29$, $\mathrm{CI}=0.20-0.41)$ and oncologic patients were not at an increased undernutrition risk.

Similar patterns were observed when the association between the same risk factors and undernutrition defined by anthropometric criteria was studied (Table 3 ). The two estimates lead to a similar pattern of multivariate odds ratios, however the NRS 2002 estimates resulted in more significant findings. The loss of functional autonomy was significantly associated with anthropometrical undernutrition, dependent patients were at an increased risk of undernutrition, $\mathrm{OR}=1.96(\mathrm{CI}=1.16-3.29)$ compared to independent patients. Smoking was the strongest risk factor associated with anthropometric undernutrition, with an adjusted $\mathrm{OR}=2.46(\mathrm{CI}=1.38-4.39)$. Being single, divorced or widowed was also significantly associated with increased risk of anthropometrical undernutrition ( $\mathrm{OR}=2.10, \mathrm{CI}=1.30-3.40)$. Patients submitted to surgical treatment compared to patients submitted to non-surgical treatment were at lower anthropometrical undernutrition risk $(\mathrm{OR}=0.40, \mathrm{CI}=0.22-0.72)$ (Table 3).

Table 2

Characteristics of the sample by NRS 2002 and undernutrition (anthropometry) status.

\begin{tabular}{|c|c|c|c|c|c|c|}
\hline \multirow[t]{2}{*}{ Characteristic } & \multicolumn{2}{|l|}{ NRS $2002(n=1144)$} & \multirow[t]{2}{*}{$p$} & \multicolumn{2}{|c|}{ Undernutrition (anthropometry) ${ }^{\mathrm{a}}(n=1044)$} & \multirow[t]{2}{*}{$p$} \\
\hline & With risk $(n=412)$ & Without risk $(n=732)$ & & Yes $(n=101)$ & No $(n=943)$ & \\
\hline \multicolumn{7}{|l|}{$\operatorname{Sex}(n(\%))$} \\
\hline Female & $197(47.8)$ & $377(52.2)$ & 0.231 & $45(44.6)$ & $480(55.4)$ & 0.225 \\
\hline Male & $215(52.2)$ & $355(47.8)$ & & $56(55.4)$ & $463(44.6)$ & \\
\hline \multicolumn{7}{|l|}{ Age $(n(\%))$} \\
\hline $18-64$ years & $157(38.1)$ & $527(72.0)$ & $<0.001$ & $54(53.5)$ & $586(62.1)$ & 0.089 \\
\hline$\geq 65$ years & $255(61.9)$ & $205(28.0)$ & & $47(46.5)$ & $357(37.9)$ & \\
\hline \multicolumn{7}{|l|}{ Education ( $n(\%))$} \\
\hline None & $170(41.3)$ & $75(10.2)$ & $<0.001$ & $37(36.6)$ & $168(17.8)$ & $<0.001$ \\
\hline $1-4$ years & $167(40.5)$ & $389(53.1)$ & & $36(35.6)$ & $487(51.6)$ & \\
\hline$>4$ years & $75(18.2)$ & $268(36.6)$ & & $28(27.7)$ & $288(30.5)$ & \\
\hline Married/marriage like ( $n(\%))$ & $196(47.6)$ & $525(71.7)$ & $<0.001$ & $44(43.6)$ & $622(66.0)$ & $<0.001$ \\
\hline \multicolumn{7}{|l|}{ Underlying disease ( $n(\%))$} \\
\hline Medical & $264(64.1)$ & $282(38.5)$ & $<0.001$ & $59(58.4)$ & $414(43.9)$ & 0.002 \\
\hline Surgical & $61(14.8)$ & $292(39.9)$ & & $17(16.8)$ & $320(33.9)$ & \\
\hline Oncological & $87(21.1)$ & $158(21.6)$ & & $25(24.8)$ & $209(22.2)$ & \\
\hline \multicolumn{7}{|l|}{ Functional autonomy $(n(\%))$} \\
\hline 6 activities & $180(43.7)$ & $455(62.2)^{\mathrm{b}}$ & $<0.001$ & $44(43.6)$ & $548(58.1)$ & $<0.001$ \\
\hline $3-5$ activities & $84(20.4)$ & $133(18.2)$ & & $19(18.8)$ & $176(18.7)$ & \\
\hline $0-2$ activities & $148(35.9)$ & $144(19.7)$ & & $38(37.6)$ & $219(23.2)$ & \\
\hline Smoking status ( $n(\%))$ & $53(12.9)$ & $125(17.1)$ & 0.059 & $24(23.8)$ & $143(15.2)$ & 0.025 \\
\hline
\end{tabular}

a Patients with ascites $(n=25)$ and/or oedema $(n=90)$ were excluded from this analysis $(n=100)$.

b Total adds $>100 \%$ due to rounded values. 
Table 3

Factors associated with undernutrition risk (NRS $2002 \geq 3$ ) and with anthropometrical undernutrition.

\begin{tabular}{|c|c|c|c|c|}
\hline & \multicolumn{2}{|c|}{ Undernutrition risk ${ }^{\mathrm{a}}$} & \multicolumn{2}{|l|}{ Undernutrition $^{\mathrm{b}}$} \\
\hline & Crude OR (CI) & Adjusted $\mathrm{OR}^{\mathrm{c}}(\mathrm{CI})$ & Crude OR (CI) & Adjusted $\mathrm{OR}^{\mathrm{C}}(\mathrm{CI})$ \\
\hline \multicolumn{5}{|l|}{ Sex } \\
\hline Female & 1 (referent) & 1 (referent) & 1 (referent) & 1 (referent) \\
\hline Male & $1.16(0.91,1.48)$ & $1.61(1.19,2.16)$ & $1.29(0.85,1.95)$ & $1.40(0.89,2.20)$ \\
\hline Age $^{\mathrm{d}}$ (years) & $1.05(1.04,1.06)$ & $1.03(1.02,1.04)$ & $1.01(1.00,1.02)$ & $1.00(0.99,1.02)$ \\
\hline \multicolumn{5}{|l|}{ Education (school years) } \\
\hline$>4$ & 1 (referent) & 1 (referent) & 1 (referent) & 1 (referent) \\
\hline $1-4$ & $1.53(1.12,2.10)$ & $0.87(0.60,1.26)$ & $0.76(0.45,1.27)$ & $0.69(0.38,1.27)$ \\
\hline 0 & $8.10(5.58,11.77)$ & $2.45(1.52,3.96)$ & $2.27(1.34,3.84)$ & $1.52(0.72,3.21)$ \\
\hline \multicolumn{5}{|l|}{ Marital status } \\
\hline Married/marriage like & 1 (referent) & 1 (referent) & 1 (referent) & 1 (referent) \\
\hline Single/divorced/widowed & $2.80(2.17,3.59)$ & $1.83(1.34,2.51)$ & $2.51(1.66,3.80)$ & $2.10(1.30,3.40)$ \\
\hline \multicolumn{5}{|l|}{ Underlying disease } \\
\hline Medical & 1 (referent) & 1 (referent) & 1 (referent) & 1 (referent) \\
\hline Surgical & $0.22(0.16,0.31)$ & $0.29(0.20,0.41)$ & $0.37(0.21,0.65)$ & $0.40(0.22,0.72)$ \\
\hline Oncological & $0.59(0.43,0.80)$ & $0.95(0.66,1.36)$ & $0.84(0.51,1.38)$ & $1.42(0.81,2.47)$ \\
\hline \multicolumn{5}{|l|}{ Functional autonomy } \\
\hline 6 activities & 1 (referent) & 1 (referent) & 1 (referent) & 1 (referent) \\
\hline $3-5$ activities & $1.60(1.16,2.21)$ & $1.33(0.90,1.96)$ & $1.35(0.77,2.36)$ & $1.70(0.91,3.17)$ \\
\hline $0-2$ activities & $2.60(1.95,3.46)$ & $1.69(1.20,2.39)$ & $2.16(1.36,3.43)$ & $1.96(1.16,3.29)$ \\
\hline \multicolumn{5}{|l|}{ Smoking status } \\
\hline Non-smoker & 1 (referent) & 1 (referent) & 1 (referent) & 1 (referent) \\
\hline Smoker & $0.71(0.51,1.01)$ & $1.55(1.02,2.35)$ & $1.74(1.07,2.85)$ & $2.46(1.38,4.39)$ \\
\hline
\end{tabular}

a $n=1144$.

b $n=1044$.

c Multivariated logistic regression model.

d Entered on the model as continuous variable.

When the association between the studied risk factors and undernutrition risk was evaluated for patients aged $\geq 65$ years, an increased effect of age ( $\mathrm{OR}=1.07 \mathrm{CI}=1.04-1.11)$ and illiteracy $(\mathrm{OR}=2.72 \mathrm{CI}=1.32-5.59)$ was found. The loss of functional autonomy remains significantly associated with undernutrition risk $(\mathrm{OR}=1.80 \mathrm{CI}=1.07-3.04)$. The other factors associated with undernutrition identified in the entire sample lost their statistical significance, namely males, single/divorced/widowed individuals, patients submitted to surgical treatment and smokers. Using anthropometrical undernutrition as a dependent variable, being single/divorced/widowed was the only factor associated with an increased risk ( $\mathrm{OR}=2.83 \mathrm{CI}=1.19-6.69)$. The other associations previously identified for the total sample analysis lost their statistical significance.

\section{Discussion}

This cross-sectional study shows that in this sample, undernutrition risk exists in more than one of every three patients in the participating hospitals in Portugal. This proportion varies according to the health care institution and is in line with studies conducted in Europe, ${ }^{2,4,6,26}$ America $^{3,27}$ and Japan. ${ }^{3}$ The anthropometrical undernutrition is present in $9.7 \%$ of the studied patients, a lower proportion than previously reported..$^{20}$

Our results clearly reveal an association between low autonomy in Katz's activities of daily living with undernutrition risk (by NRS 2002) and anthropometrical undernutrition at hospital admission, after adjusting for known risk factors in this mixed sample of older adults and adults. Though this association between undernutrition and functional status evaluated at hospital admission has not been previously quantified, these findings are in agreement with previously described in studies conducted in other settings, notwithstanding the use of different nutritional tools. Cross-sectional data conducted amongst elderly residents in nursing homes in Finland ${ }^{28}$ and amongst community-dwelling older adults in China, ${ }^{29}$ described functional status as one of most important factors associated with nutritional status. There also exists evidence supporting that nutritional decline precedes the functional impairment in older adults. ${ }^{12}$ Undernutrition in older hospitalized patients submitted to non-surgical treatment assessed by Subjective Global Assessment was strongly associated with later dependency in activities of daily living, three months after hospital discharge. ${ }^{12}$ Important findings from a recent prospective study of older French individuals who were independent at baseline and hospitalized in emergency, showed that undernutrition risk detected by the Mini Nutritional Assessment Short Form was an early indicator of loss of independence 30 days after hospitalization. ${ }^{11}$

The present data shows that low educational status was the highest risk factor independently associated with undernutrition risk and this effect was stronger for patients aged $\geq 65$ years. These results are in line with previous findings. ${ }^{7,8}$ However, the cut offs established in the present study were much lower, of 4 versus $<12$ completed years of school, ${ }^{7,8}$ due to a high proportion of patients with a low educational level. The educational status could be linked to deprivation, ${ }^{9}$ which has been shown to be closely connected with in-hospital undernutrition or with several well known risk factors for undernutrition, such as poor health care. ${ }^{9}$ It can also reflect poor knowledge and competencies to deal with the disease process. Being single/divorced/widowed increased the risk of undernutrition and as well of anthropometrical undernutrition, perhaps reflecting the increased probability of living alone and social isolation which has been widely described as a risk factor for undernutrition. ${ }^{7,8}$ It cannot be ruled out that this multicentric hospital sample could be biased toward lower social classes, as more educated individuals are more likely to be able to choose private health care institutions in order to obtain medical treatment. Nevertheless, the present study sample could represent a target population where preventive interventions to improve 
nutritional status, to modify educational level and functional ability may be more effective in reducing disease-related undernutrition.

The finding that smoking status was the strongest independent risk factor for anthropometrical undernutrition is consistent with a decreased food intake, related to tobacco induced anorexia, ${ }^{1}$ and similar to previous findings linking tobacco consumption and undernutrition assessed by the Subjective Global Assessment, ${ }^{7}$ perhaps indicating unhealthy lifestyles. ${ }^{30}$

Our results showed that oncologic patients were not at an increased undernutrition risk compared to patients submitted to non-surgical treatment. These findings are similar to a study conducted in Barcelona, ${ }^{20}$ but diverge with others. ${ }^{6,27}$ In the present study, patients submitted to surgical treatment have a frequency of undernutrition risk of $14.8 \%$ and of undernutrition of $16.8 \%$, as previously reported in the German Malnutrition Study, ${ }^{6}$ where patients admitted to surgical treatment hospitals showed a low frequency of undernutrition of $13.6 \%$ (Subjective Global Assessment $B+C$ ). When our patients submitted to surgical treatment were compared to those with underlying non-surgical diseases, they showed an independent lower undernutrition risk that remains unchanged after multivariate adjustments, perhaps reflecting better nutritional care before hospital admission.

Age was associated with undernutrition risk, being higher for patients aged $\geq 65$ years. Although these results are comparable to those previously published describing this association, ${ }^{1,6}$ the overestimation of undernutrition risk related to age itself cannot be ruled out for NRS 2002 scoring, because age contributed with one point if the patient was 70 years or over. Otherwise, our results did not show an association between age and anthropometrical undernutrition, meaning that this problem is prevalent across all age groups of the studied sample.

Several strengths and limitations of this study should be further recognized. The systematic sampling procedure used in this study could be regarded as a strength, as it allowed us to obtain a probabilistic sample covering a variety of clinical diagnosis and ensuring a wide spectrum of nutritionally relevant pathologies. The undernutrition risk patients were identified by the NRS 2002, a valid and practical screening tool, ${ }^{2,3}$ recommended by the European Society for Clinical Nutrition and Metabolism (ESPEN). The anthropometrical criteria, including the MMC, which is traditionally recognized as a reliable indicator of undernutrition, ${ }^{22,23}$ were further used to obtain an independent contribution to the diagnosis.

Some limitations of this study merit further discussion. First, its cross-sectional design did not allow the exploration of a causal relation between the identified factors and undernutrition. Secondly, the selected hospitals were recruited on a convenience basis, which can limit the generalization of our findings to all hospitals. Third, the exclusion criteria were established in order to exclude patients whose clinical conditions were more likely to be related to a poor nutritional status, such as children and critical care patients. This limits the ability of the present analysis to evaluate the factors associated with these situations and leads certainly to an underestimation of both undernutrition risk and anthropometric undernutrition. Fourth, although the scale used to evaluate functional ability (the Index of Independence in Activities of Daily Living) has been widely used, ${ }^{10,11}$ it is acknowledged that minor illness or disability frequently do not translate into the limitations in basic activities of daily living covered in this scale. ${ }^{10}$ Therefore, the significant association between the loss of functional ability and undernutrition could have been underestimated in the present analysis. Other factors as depression ${ }^{31}$ and cognitive impairment ${ }^{8}$ that have been related to malnutrition were not evaluated in the present study. Furthermore, the majority of associations previously identified for the total sample analysis, lost their statistical significance when the association between the studied risk factors with both undernutrition risk and anthropometrical undernutrition was evaluated separately for patients aged $\geq 65$ years. The small number of patients in some strata of this analysis and also with anthropometrical undernutrition, leads to insufficient statistical power that might further limit our ability to identify significant associations. Finally, although adjustments were made for a variety of potential confounding factors, residual confounding could not be ruled out.

In conclusion, the present study shows in this sample with a large proportion of patients at risk and undernourished, that factors associated with undernutrition risk were age, a low educational level and being male, single, divorced or widowed, be a smoker and impaired functional status. Similar patterns were observed for the multivariate association between the anthropometric undernutrition and the following parameters: impaired functional status, single divorced or widowed individuals and smokers. Both the undernutrition risk and anthropometric undernutrition estimates lead to a similar pattern of multivariate odds ratios, however, the NRS 2002 estimates resulted in more significant findings. We also conclude that little extra information is gained by using anthropometrical indices compared to NRS 2002 when assessing the factors associated with undernutrition.

These findings present a challenge for primary health care professionals, highlighting the need to implement preventive strategies at community level, before hospital admission.

\section{Conflict of interest}

The authors have no conflict of interest.

\section{Statement of authorship}

TFA, LCM and MMT contributed to the study design. Data collection and analysis was performed by LCM, MAT, MMT, LA e AA. The paper was written by TFA and LCM and edited by all the authors. All the authors read and approved the final manuscript.

\section{Acknowledgements}

The data collection in two hospitals was possible due to a grant from "Programa Investigação Científica na Pré-graduação", to MMT and LCM from "Fundação Ilídio Pinho, Caixa Geral de Depósitos and Reitoria da Universidade do Porto". The sponsors had no involvement in this study. The authors would like to thank the directors of involved hospitals and the heads and the staff of the different departments for their support in the hospitals involved in the study.

We are especially grateful to our colleague Andreia Henriques for data collection and preparation in one hospital.

\section{References}

1. Stratton RJ, Green CJ, Elia M. Disease-related malnutrition: an evidence based approach to treatment. In: Stratton RJ, Green CJ, Elia M, editors. Prevalence of disease-related malnutrition. Wallingford, United Kingdom: CABI Publishing. 2003. p. 35-92.

2. Sorensen J, Kondrup J, Prokopowicz J, Schiesser M, Krähenbühl L, Meier R, et al, EuroOOPS study group. EuroOOPS: an international, multicentre study to implement nutritional risk screening and evaluate clinical outcome. Clin Nutr 2008;27:340-9.

3. Liang X, Jiang ZM, Nolan MT, Efron DT, Kondrup J. Comparative survey on nutritional risk and nutritional support between Beijing and Baltimore teaching hospitals. Nutrition 2008;24:969-76.

4. Lamb CA, Parr J, Lamb EI, Warren MD. Adult malnutrition screening, prevalence and management in a United Kingdom hospital: cross-sectional study. Br J Nutr 2009;10:1-5.

5. Meijers JM, Candel MJ, Schols JM, van Bokhorst-de van der Schueren MA, Halfens RJ. Decreasing trends in malnutrition prevalence rates explained by regular audits and feedback. J Nutr 2009;139:1381-6.

6. Pirlich M, Schütz T, Norman K, Gastell S, Lübke HJ, Bischoff SC, et al. The German hospital malnutrition study. Clin Nutr 2006;25:563-72. 
7. Pirlich M, Schutz T, Kemps M, Luhman N, Minko N, Lübke HJ, et al. Social risk factors for hospital malnutrition. Nutrition 2005;21:295-300.

8. Feldblum I, German L, Castel H, Harman-Boehm I, Bilenko N, Eisinger M, et al. Characteristics of undernourished older medical patients and the identification of predictors for undernutrition status. Nutr J 2007;6:37.

9. Stratton RJ, Elia M. Deprivation linked to malnutrition risk and mortality in hospital. Br J Nutr 2006;96:870-6.

10. Katz S. Assessing self-maintenance. Activities of daily-living, mobilidity and instrumental activities of daily living. I Am Geriatr Soc 1983;21:721-7.

11. Lang PO, Meyer N, Heitz D, Dramé M, Jovenin N, Ankri J, et al. Loss of independence in Katz's ADL ability in connection with an acute hospitalization: early clinical markers in French older people. Eur J Epidemiol 2007;22 621-30.

12. Covinsky K, Martin G, Beyth R, Justine A, Sehgal A, Landefeld C. The relationship between clinical assessments of nutritional status and adverse outcomes in older hospitalized medical patients. J Am Geriatr Soc 1999;47: 532-8.

13. Matos L, Teixeira MA, Henriques A, Tavares MM, Alvares L, Antunes A, et al [Nutritional status recording in hospitalized patient notes]. Acta Med Port 2007;20:503-10.

14. Matos LC, Tavares MM, Amaral TF. Handgrip strength as a hospital admission nutritional risk screening method. Eur J Clin Nutr 2007;61:1128-35.

15. Amaral TF, Antunes A, Cabral S, Alves P, Kent-Smith L. An evaluation of three nutritional screening tools in a Portuguese oncology centre. J Hum Nutr Diet 2008;21:575-83.

16. Amaral TF, Matos LC, Tavares MM, Subtil A, Martins R, Nazaré M, et al. The economic impact of disease-related malnutrition at hospital admission. Clin Nutr 2007;26:778-84

17. Guidelines for the use of parenteral and enteral nutrition in adult and pediatric patients. J Parenter Enteral Nutr 2002;26:1SA-138SA.

18. World Medical Association. Declaration of Helsinki. Tokyo, http://www.wma net/e/policy/b3.htm; 2004 [accessed 16.07.09].
19. Kondrup J, Rasmussen HH, Hamberg O, Stanga Z, ad hoc ESPEN Working Group. Nutritional risk screening (NRS 2002): a new method based on an analysis of controlled clinical trials. Clin Nutr 2003;22:321-36.

20. Planas M, Audivert S, Pérez-Portabella C, Burgos R, Puiggrós C, Casanelles J. Nutritional status among adult patients admitted to an university-affiliated hospital in Spain at the time of genoma. Clin Nutr 2004;23:1016-24.

21. Lee RD, Nieman DC. Nutritional assessment of hospitalized patients. In: Lee RD, Nieman DC, editors. Nutritional assessment. St. Louis: Mosby; 1995. p. 289-332.

22. Jelliffe DB. Monograph series No. 53. The assessment of the nutritional status of the community, vol. 50. Geneva, Switzerland: World Health Organization; 1966.

23. Frisancho AR. New norms of upper limb fat and muscle areas for assessment of nutritional status. Am J Clin Nutr 1981;34:2540-5.

24. Bishop CW, Bowen PE, Ritchey SJ. Norms for nutritional assessment of American adults by upper arm anthropometry. Am J Clin Nutr 1981;34:2530-9.

25. Corish CA, Kennedy NP. Anthropometric measurements from a cross-sectional survey of Irish free-living elderly subjects with smoothed centile curves. $\mathrm{Br} \mathrm{J}$ Nutr 2003;89:137-45.

26. Imoberdorf R, Meier R, Krebs P, Hangartner PJ, Hess B, Stäubli M, et al. Prevalence of undernutrition on admission to Swiss hospitals. Clin Nutr 2010;29: $38-41$.

27. Correia I, Campos A. Prevalence of hospital malnutrition in Latin American: the multicenter ELAN study. Nutrition 2003;19:823-5.

28. Suominen $M$, Muurinen S, Routasalo $P$, Soini $H$, Suur-Uski I, Peiponen A et al Malnutrition and associated factors among aged residents in all nursing homes in Helsinki. Eur J Clin Nutr 2005;59:578-83.

29. Han Y, Li S, Zheng Y. Predictors of nutritional status among communitydwelling older adults in Wuhan, China. Public Health Nutr 2009;12:1189-96.

30. Lopez AD, Mathers CD. Measuring the global burden of disease and epidemiological transitions: 2002-2030. Ann Trop Med Parasitol 2006;5-6:481-99.

31. German L, Feldblum I, Bilenko N, Castel H, Harman-Boehm I, Shahar DR. Depressive symptoms and risk for malnutrition among hospitalized elderly people. J Nutr Health Aging 2008;12:313-8. 